\title{
The effect of intensive hemodialysis on pulmonary arterial pressure and left ventricular systolic function in patients with end-stage renal disease; a prospective clinical trial
}

\author{
Nehzat Akiash $^{1}{ }^{\circledR}$, Shahla Ahmadi Halili ${ }^{*}{ }^{\circledR}$, Forough Darabi $^{1}{ }^{\circledR}$, Maryam Moradi $^{3}$ \\ ${ }^{1}$ Atherosclerosis Research Center, Ahvaz Jondishapur University of Medical Sciences, Ahvaz, Iran \\ ${ }^{2}$ Chronic Renal Failure Research Center, Ahvaz Jundishapur University of Medical Sciences, Ahvaz, Iran \\ ${ }^{3}$ Department of Biostatistics and Epidemiology, School of Public Health, Ahvaz Jundishapur University of Medical Sciences, Ahvaz, Iran
}

\section{A R T I C L E I N F O}

Article Type:

Original

\section{Article History:}

Received: 19 July 2020

Accepted: 4 October 2020

Published online: 26 October 2020

\section{Keywords:}

Chronic kidney disease

Hemodialysis

Pulmonary hypertension

Global longitudinal strain

\begin{abstract}
A B S T RA C T
Introduction: End-stage renal disease (ESRD) requires hemodialysis or kidney transplantation for the patients to survive.

Objectives: The present study was conducted to examine whether intensive hemodialysis and hemoglobin $(\mathrm{Hb})$ concentration correction can improve left ventricular (LV) function and pulmonary arterial hypertension in ESRD patients?

Patients and Methods: This prospective clinical trial was designed to examine patients referring to public hospitals in Ahvaz, Iran, in 2016-2017. All the patients treated with intensive hemodialysis for two months were included in the study. The Hb concentration was corrected by the subcutaneous injection of erythropoietin at the dose of 50-150 IU/kg three times per week.

Results: Thirty-one ESRD patients with high pulmonary arterial pressure participated in this study. After the intervention, blood $\mathrm{Hb}$ levels increased significantly in the ESRD patients from $9.20 \pm 1.39 \mathrm{~g} / \mathrm{dL}$ to $10.96 \pm 1.01 \mathrm{~g} / \mathrm{dL}(P<0.0001)$. Pulmonary arterial pressure decreased significantly from $53.52 \pm 10.63 \mathrm{mmHg}$ to $43.32 \pm 10.92 \mathrm{~mm} \mathrm{Hg}(P<0.0001)$. Left ventricular ejection fraction increased significantly based on the visual assessment and Simpson's method (2D echocardiography) from $41.06 \pm 10.76$ to $43.00 \pm 11.28$ and $46.26 \pm 13.72$ to $48.36 \pm 13.90$, respectively $(P<0.0001)$. Absolute value of two dimensional global longitudinal strain $(\mathrm{GLS})$ increased significantly from $13.99 \pm 5.05$ to $15.14 \pm 5.32(P<0.0001)$ after the intervention. Conclusion: Intensive hemodialysis for two months resulted in a significant increase in $\mathrm{Hb}$ concentrations, improved the LV systolic function and decreased pulmonary hypertension in ESRD patients.

Trial registration: The trial protocol was approved in the Iranian Registry of Clinical Trials (identifier: IRCT20180212038705N1, https://www.irct.ir/trial/29593; Ethic code: IR.AJUMS. REC.1396.911).
\end{abstract}

Implication for health policy/practice/research/medical education:

In our prospective clinical trial on 31 patients with high pulmonary arterial pressure, we found intensive hemodialysis for two months resulted in a significant increase in $\mathrm{Hb}$ levels in patients and a decrease in pulmonary arterial pressure.

Please cite this paper as: Akiash N, Ahmadi Halili S, Darabi F, Moradi M. The effect of intensive hemodialysis on pulmonary arterial pressure and left ventricular systolic function in patients with end-stage renal disease; a prospective clinical trial. J Renal Inj Prev. 2021; 10(3): e22. doi: 10.34172/jrip.2021.22.

\section{Introduction}

End-stage renal disease (ESRD) requires hemodialysis or kidney transplantation for the patients to have a proper quality of life (1). According to the United States Renal Data System (USRDS) reports released in 2015, there were approximately 500000 cases of ESRD receiving hemodialysis treatment and more than $40 \%$ had received kidney transplantation (2).

Pulmonary hypertension (PHT) is a progressive disorder that leads to cardiovascular, pulmonary and 
systemic diseases and other complications with a significant morbidity and mortality (3). Pulmonary arterial hypertension (PAH) is characterized by right ventricular (RV) dysfunction and increases pulmonary artery pressure, thus resulting in the malfunction of the left ventricular (LV) myocardium (4). Screening for PAH among patients undergoing hemodialysis is therefore vital $(5,6)$. Compared to conventional hemodialysis, intensive hemodialysis could be associated with better survival rates and improved physical and mental health and quality of life $(7,8)$.

Anemia is an independent predictor of renal dysfunction (such as ESRD) and poor erythropoietin production (9). Anemia may also have a positive correlation with cardiovascular disorders such as pulmonary arterial pressure, right ventricular hypertrophy, RV failure and premature death $(9,10)$.

\section{Objectives}

The present study was conducted to examine whether intensive hemodialysis and hemoglobin concentration correction can improve LV function and pulmonary arterial pressure in ESRD patients.

\section{Patients and Methods}

\section{Study design}

In this prospective clinical trial, the inclusion criteria consisted of giving informed consent, Patient with ESRD, age over 18 years and systolic pulmonary artery pressure (sPAP) $>40 \mathrm{~mm} \mathrm{Hg}$. The exclusion criteria consisted of having pulmonary parenchymal and vascular diseases, such as acute or chronic pulmonary thromboembolism and chronic obstructive pulmonary disease, serum ferritin levels less than $200 \mathrm{ng} / \mathrm{mL}$, transferrin saturation less than $20 \%$ and valvular heart diseases such as flail leaflet of the mitral valve, a recent myocardial infarction and an acute illness altering hematocrit levels, such as acute bleeding or acute infection.

\section{Therapeutic intervention, clinical and laboratory}

All the patients were treated with intensive hemodialysis for two months. They received hemodialysis four times a week after reaching dry weight. The mean hemoglobin $\mathrm{Hb}$ ) before taking erythropoietin and after $\mathrm{Hb}$ correction was measured and recorded at the end of the study (i.e. two months later). Hemoglobin concentration was corrected by the subcutaneous injection of erythropoietin at the dose of 50-150 IU/kg three times per week.

\section{Standard echocardiography and strain analysis by speckled tracking method}

Two-dimensional echocardiography examination was performed for all the patients, including the twodimensional method, color Doppler study and tissue Doppler echocardiography (global longitudinal strain by the speckle tracking method), using Vivid E9 ultrasound system (USA, GE Ultrasound) before and after the intensive hemodialysis. Transthoracic echocardiography was performed to determine the LV systolic function using the biplane Simpson's method at least three times, and the mean value was calculated for each patient. Other echocardiographic parameters, including PAP and LV diastolic function, were recorded for all the patients and global longitudinal strain (GLS) was measured by the 2D method. GLS using speckle tracking echocardiography offline analysis with 2D speckle tracking software was performed for the evaluation of LV GLS. Apical 4, 3 and 2 chamber views were selected (Figure 1). The longitudinal strain was calculated based on the entire traced LV contour (Figure 2). GLS by 2D STE, strain's curves (Figure 3) and a bull's eye map of each segment (Figure 4) were finally determined. Tricuspid valve regurgitation velocity was measured through the apical four chamber view using continuous wave Doppler echocardiography. sPAP was then calculated according to the modified Bernoulli equations, as follows:

$P A S P=4 \times(\text { Tricuspid regurgitation jet velocity })^{2}+$ (Estimated right atrial pressure)

In this study, a sPAP above $40 \mathrm{~mm} \mathrm{Hg}$ was defined as a criterion for the presence of PHT.

Left ventricular systolic dysfunction was defined as LVEF $<50 \%$. Left ventricular diastolic function (LVDD) was evaluated according to diastolic guidelines (Impaired relaxation; early mitral inflow peak velocity/ late mitral inflow velocity $(\mathrm{E} / \mathrm{A})<0.8$, deceleration time $(\mathrm{DT})>240$ $\mathrm{ms}$ and Early mitral inflow peak velocity/early diastolic mitral annular velocity (E/e' at the septal annulus) $<0.8$, pseudo-normal pattern: $(\mathrm{E} / \mathrm{A}=0.8-2, \mathrm{DT}=160-240 \mathrm{~ms}$ and increased $\left.\mathrm{E} / \mathrm{e}^{\prime}\right)$ and restrictive pattern; (E/A $>2, \mathrm{DT}$ $<160 \mathrm{~ms}$ and increased $\mathrm{E} / \mathrm{e}^{\prime}$ at the septal annulus).

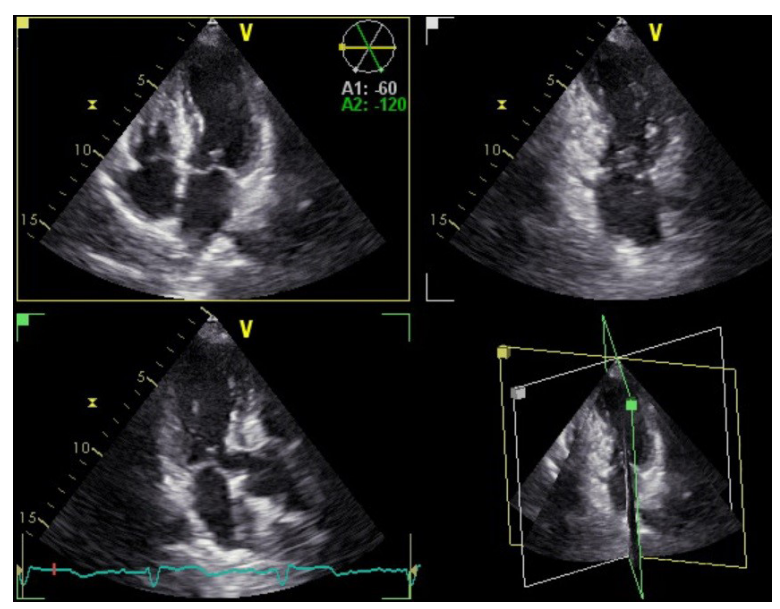

Figure 1. Two-, three- and four-chamber views for evaluation of longitudinal strain. 

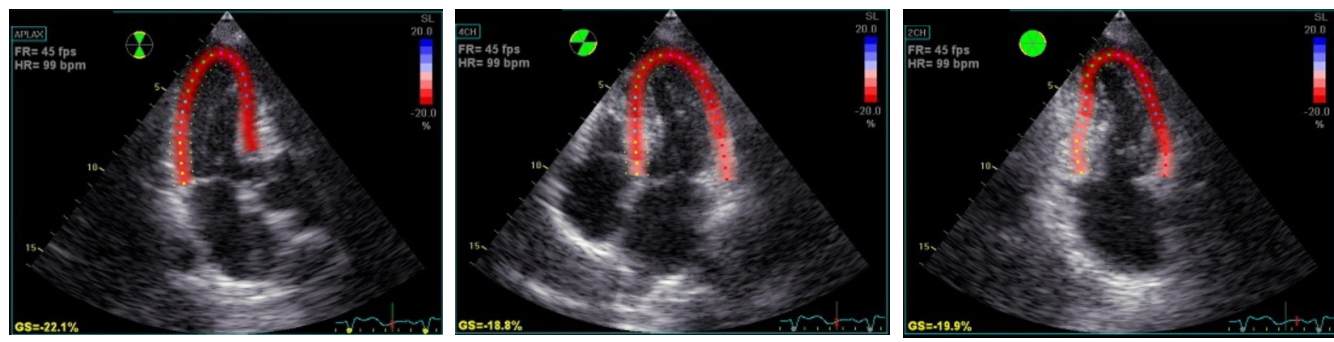

Figure 2. LV contour was traced in all three views for evaluation of longitudinal strain

\section{Ethical issues}

The study was in accordance with the Declaration of Helsinki and its later amendments. This paper was extracted from the residential thesis of Forough Darabi, at the department of internal medicine and advanced

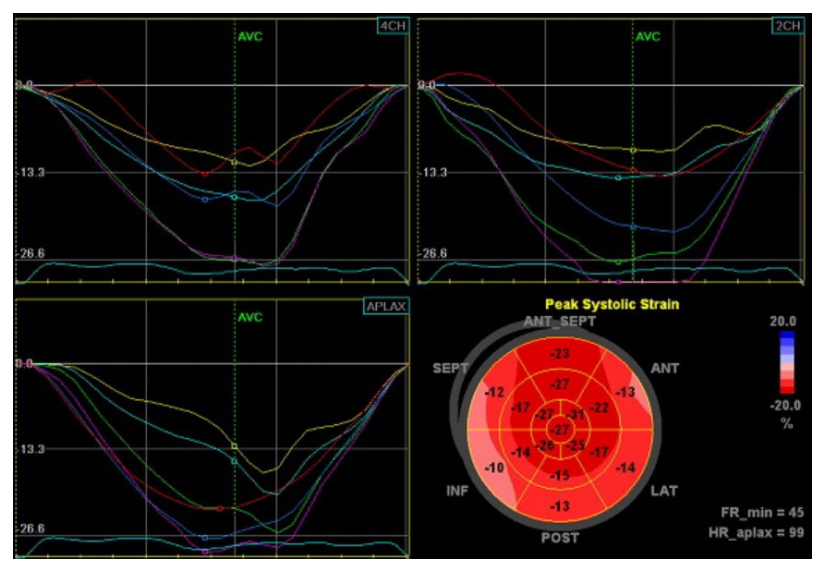

Figure 3. Bull's eye map and strain curves.

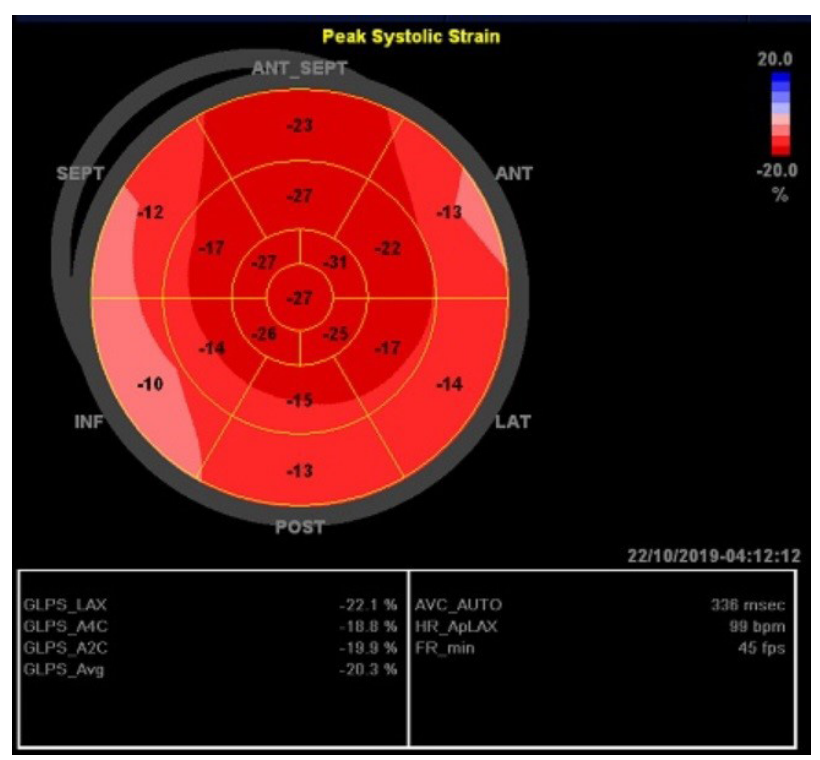

Figure 4. Bull's eye map with average global longitudinal strain (GLS) of 2, 3 and 4 chamber views. echocardiography ward of Ahvaz Jundishapur University of Medical Sciences. This prospective clinical trial was approved by the ethics committee of the Ahvaz Jundishapur University of Medical Sciences (\# IR.AJUMS. REC.1396.911). All the participants were informed about the study aims and procedures. Informed consent process was performed for all the patients. The trial protocol was also approved in the Iranian Registry of Clinical Trials (identifier: IRCT20180212038705N1, https://www.irct.ir/ trial/29593).

\section{Statistical analysis}

After collecting the data, descriptive statistics including mean, standard deviation and frequency were measured. Depending on the normality of the distribution of the quantitative variables, the independent t-test or MannWhitney test was used, and in the case of the qualitative variables, the chi-square test was used to compare the mean of the variables between the two groups. A $P$ value less than 0.05 was considered statistically significant. All the analyses were performed in SPSS 20 for Windows.

\section{Results}

Intensive dialysis and $\mathrm{Hb}$ correction were carried out for the 31 ESRD patients with high PAH (Figure 5). The mean age of the participants was $54.68 \pm 14.85$ (range 29 to 85 ) years. The mean duration of the disease was $3.45 \pm 2.42$ (range 1 to 9 ) years and the duration of dialysis was $3.43 \pm 2.26$ (range 1 to 9 ) years.

The most commonly used medication was erythropoietin (93.5\%). Table 1 presents the other baseline characteristics of the patients.

Plasma $\mathrm{Hb}$ levels increased significantly after the intervention $(P<0.0001)$. Additionally, at the end of the intervention, ferritin levels decreased significantly compared to the baseline (Table 2).

The PAP levels decreased significantly in the ESRD patients after the intervention $(P<0.001)$. After the completion of the intervention, LVEF values increased significantly $(P<0.001)$. In addition, the absolute value of GLS (using the $2 \mathrm{D}$ method) increased significantly after the intensive dialysis $(P<0.001$; Table 2$)$. 


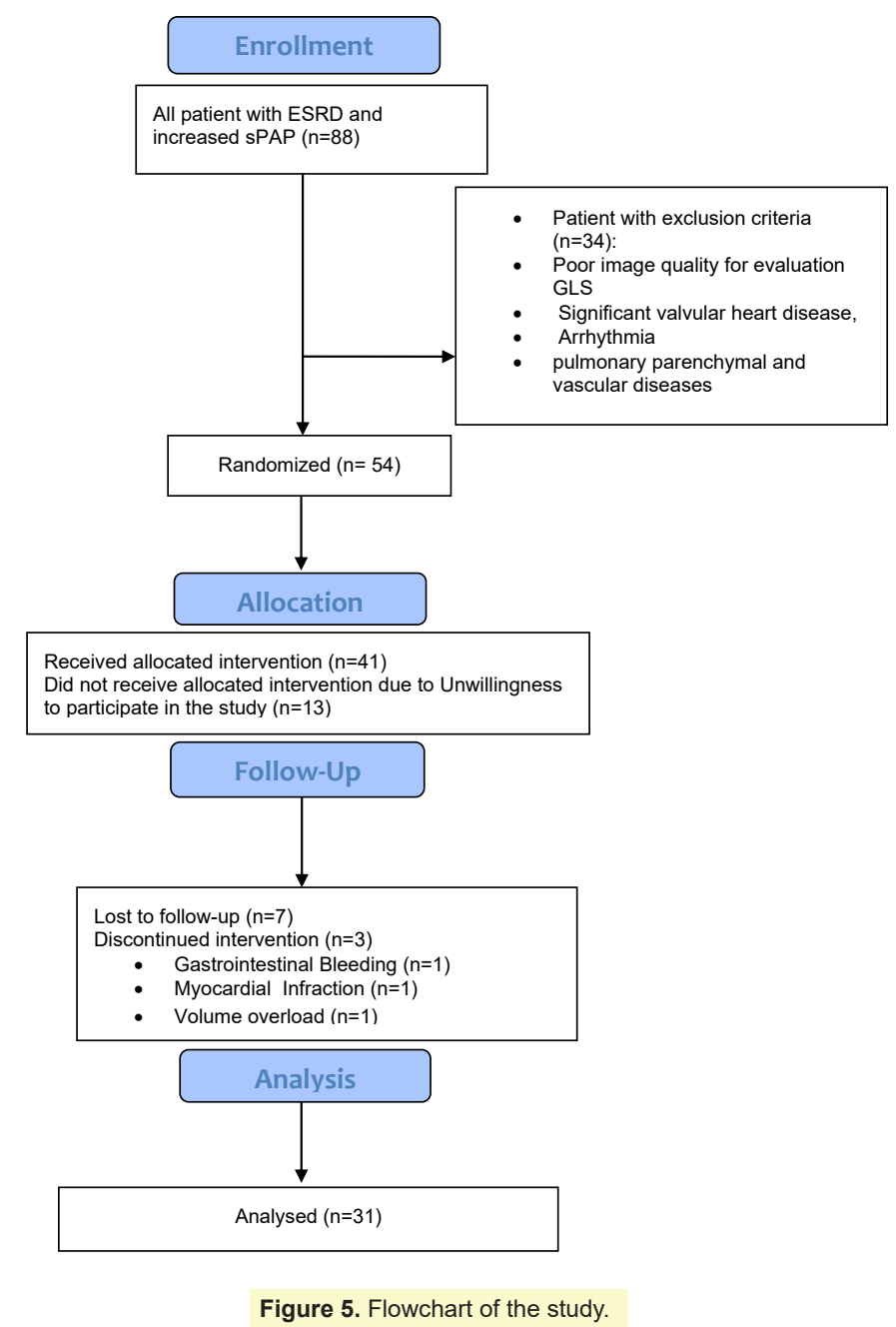

\section{Discussion}

Cardiovascular disease remains the leading cause of mortality in renal transplantation and ESRD patients $(11,12)$. PHT is defined as an increase in one of the factors affecting pulmonary vascular resistance that may be considered an independent risk factor involved in the death of hemodialysis patients $(13,14)$. Although anemia causes several abnormalities in chronic kidney disease, including erythropoietin production deficiency, reduced erythrocyte survival and uremic accumulation, it is also proposed as a significant risk factor for cardiovascular diseases with adverse outcomes $(15,16)$. Walker et al demonstrated a close relationship between cardiovascular pathology and anemia in patients with elevated serum creatinine (17). Correcting anemia and maintaining $\mathrm{Hb}$ levels in the standard range using erythropoiesis stimulating agents are very important for managing these patients (18-20). Although intensive hemodialysis may be associated with an increased risk of clinical problems $(21,22)$, many studies have reported that intensive hemodialysis can improve cardiac mass and decrease intradialytic hypotension with favorable clinical outcomes
$(7,8,23,24)$.

The results of the present study showed that $\mathrm{Hb}$ levels increased significantly in patients after two months of intensive hemodialysis (four days per week) and erythropoietin administration. This intervention also reduced PAP significantly and improved cardiac function in ESRD patients. The improvement of cardiovascular function after $\mathrm{Hb}$ correction with erythropoietin and intensive hemodialysis has formerly been reported in some other studies. Chan et al showed that nocturnal hemodialysis, which is an emerging mode of intensive hemodialysis, improved uremic clearance, Hb levels and hematopoietic progenitor cell function significantly in patients with ESRD (20). In a similar study by Nehus et al, cardiac function improved after beginning intensive hemodialysis in pediatric patients with ESRD (25). At the beginning of the present study, $\mathrm{Hb}$ concentrations were higher than $11 \mathrm{~g} / \mathrm{dL}$ in $12.26 \%$ of the patients, while $62.29 \%$ had normal Hb concentrations, which indicates the effectiveness of the intervention.

Since metabolic disorders are associated with ESRD, hemodialysis might cause a significant reduction in 
Table 1. Baseline characteristics of patients

\begin{tabular}{|c|c|}
\hline Variables & Number (\%) \\
\hline Age (year) ${ }^{a}$ & $54.68 \pm 14.85(29-85)$ \\
\hline Gender/Female & $16(51.6)$ \\
\hline \multicolumn{2}{|l|}{$\mathrm{BMI}\left(\mathrm{kg} / \mathrm{m}^{2}\right)$} \\
\hline $18-20$ & $8(25.8)$ \\
\hline $20-25$ & $17(54.8)$ \\
\hline $25-30$ & $6(19.4)$ \\
\hline \multicolumn{2}{|l|}{ Other illness } \\
\hline DM & $15(48.4)$ \\
\hline HTN & $24(77.4)$ \\
\hline Smoking & $9(29.0)$ \\
\hline Duration of ESRD (year) ${ }^{a}$ & $3.45 \pm 2.42(1-9)$ \\
\hline Duration of hemodialysis (year) ${ }^{a}$ & $3.43 \pm 2.26(1-9)$ \\
\hline \multicolumn{2}{|l|}{ History of drug use } \\
\hline $\mathrm{CaCO} 3$ & $25(80.6)$ \\
\hline Nephrovit & $15(48.4)$ \\
\hline Sevelamer & $20(64.5)$ \\
\hline Erythropoietin & $29(93.5)$ \\
\hline Valsartan & $22(70)$ \\
\hline Amlodipine & $8(25.8)$ \\
\hline Lasix & $11(35.5)$ \\
\hline Insulin & $15(48.4)$ \\
\hline
\end{tabular}

a Data are expressed as mean \pm SD (Min-Max).

Note: BMI, body mass index; DM, diabetes mellitus; HTN, Hypertension.

end-systolic and end-diastolic LV volumes, systolic and diastolic blood pressure and increases in LV torsion and ejection fraction $(24,26,27)$. Chen et al showed that LV longitudinal strain using 3D speckle tracking and global function is superior in hemodialysis compared to nonhemodialysis patients (28). The results of current study also showed improvements in cardiac function and systolic and diastolic parameters of the left ventricle after intensive dialysis. A significant increase was reported in LVEF and also in GLS according to the echocardiographic findings. At the end of the intervention, diastolic LVDD also improved significantly compared to the beginning of the study.

In general, regular echocardiographic evaluation along with other effective therapies, such as intensive hemodialysis, is important for the early identification of cardiac involvement in patients with LV dysfunction and high PAP.

\section{Conclusion}

The results of this study showed that intensive hemodialysis for two months results in a significant increase in $\mathrm{Hb}$ levels in patients and a decrease in PAP. In addition, the evaluation of ventricular function showed significant improvements in LVEF, GLS and LV diastolic function. The treatment regimen, however, did not have any significant effects on tricuspid regurgitation and other heart valve abnormalities. As a result of the
Table 2. Para-clinic and echocardiographic data of patients (preintervention and post-intervention

\begin{tabular}{|c|c|c|c|}
\hline \multirow{2}{*}{ Variables } & \multicolumn{2}{|c|}{ Patients } & \multirow{2}{*}{$P$ value* } \\
\hline & Pre-intervention & Post-intervention & \\
\hline $\mathrm{Hb}(\mathrm{g} / \mathrm{dL})$ & $\begin{array}{c}9.20 \pm 1.39 \\
(6.70-11.80)\end{array}$ & $\begin{array}{l}10.96 \pm 1.01 \\
(9.00-13.50)\end{array}$ & 0.0001 \\
\hline $\mathrm{Cr}(\mathrm{mg} / \mathrm{dL})$ & $\begin{array}{c}7.40 \pm 2.34 \\
(4.10-13.00)\end{array}$ & $\begin{array}{c}5.61 \pm 1.81 \\
(3.10-10.30)\end{array}$ & 0.005 \\
\hline Ferritin (ng/mL) & $\begin{array}{c}358.11 \pm 183.21 \\
(200-800)\end{array}$ & $\begin{array}{c}256.27 \pm 148.71 \\
(100-570)\end{array}$ & 0.0001 \\
\hline PAP $(\mathrm{mm} \mathrm{Hg})$ & $\begin{array}{c}53.52 \pm 10.63 \\
(40-85)\end{array}$ & $\begin{array}{c}43.32 \pm 10.92 \\
(25-76)\end{array}$ & 0.0001 \\
\hline $\begin{array}{l}\text { LVEF\% (by visual } \\
\text { assessment) }\end{array}$ & $\begin{array}{c}41.06 \pm 10.76 \\
(18-53)\end{array}$ & $\begin{array}{c}43.00 \pm 11.28 \\
(18-55)\end{array}$ & 0.0001 \\
\hline $\begin{array}{l}\text { LVEF \% (Simpson } \\
\text { method) }\end{array}$ & $\begin{array}{c}46.26 \pm 13.72 \\
(20.0-65.0)\end{array}$ & $\begin{array}{l}48.36 \pm 13.90 \\
(20.00-73.00)\end{array}$ & 0.0001 \\
\hline GLS (3D) & $\begin{array}{c}13.99 \pm 5.05 \\
(6.5-24.0)\end{array}$ & $\begin{array}{c}15.14 \pm 5.32 \\
(7.0-26.0)\end{array}$ & 0.0001 \\
\hline \multicolumn{4}{|l|}{ TR valve problems } \\
\hline Mild & $4(12.90 \%)$ & $9(29.03 \%)$ & \\
\hline Moderate & $21(67.74 \%)$ & 19 (61.29\%) & \\
\hline $\begin{array}{l}\text { Moderate to } \\
\text { severe }\end{array}$ & 5 (16.13 \%) & $3(9.68 \%)$ & 0.074 \\
\hline Severe & $1(3.23 \%)$ & 0 & \\
\hline \multicolumn{4}{|l|}{ LVDD } \\
\hline $\begin{array}{l}\text { Impaired } \\
\text { relaxation }\end{array}$ & $3(9.7 \%)$ & $8(25.8 \%)$ & \\
\hline $\begin{array}{l}\text { Pseudo-normal } \\
\text { pattern }\end{array}$ & 20 (64.5\%) & $17(54.8 \%)$ & 0.006 \\
\hline Restrictive pattern & $8(25.8 \%)$ & $6(19.4)$ & \\
\hline
\end{tabular}

Note. ESRD: end-stage renal disease; $\mathrm{Hb}$ : hemoglobin; $\mathrm{Cr}$ : creatinine; PAP: pulmonary arterial pressure; LVEF: Left ventricular ejection fraction; GLS, global longitudinal strain; TR: Tricuspid valve regurgitation; LVDD: Left ventricular diastolic dysfunction.

All the variables are presented as mean \pm standard deviation (Min-Max). $P$ values $\leq 0.05$ are considered significant.

regimen used, intensive hemodialysis and $\mathrm{Hb}$ correction with erythropoietin can be used to reduce pulmonary hypertension, increase serum $\mathrm{Hb}$, and improve cardiac function in ESRD patients.

Limitations of the study

In the present study, PAP was measured using noninvasive Doppler echocardiography without direct invasive measurements (e.g. right heart catheterization). Some studies using invasive methods, however, have shown a correlation between sPAP measurements by Doppler echocardiography $(29,30)$.

\section{Acknowledgments}

We would like to express our appreciation and thanks to Mr. Sirus Khorshid and Ms. Mitra Ahmadpour for offering to help out with this project. We would also like to show our gratitude to the staff of echocardiography ward at Imam Khomeini hospital and the staff of universityaffiliated dialysis centers (Jundishapur University of Medical Sciences). 
Authors' contribution

Design of the work: NA, SAH. Data collection, design and preparation of the figures: NA, FD, SAH. Data analysis and interpretation: NA and MM. Drafting the article: NA and FD. Critical revision of the article: NA, SAH and MM.

\section{Conflicts of interest}

The authors declare that they have no competing interests.

\section{Ethical considerations}

Ethical issues (including plagiarism, misconduct, data fabrication, falsification, double publication or submission, redundancy) have been completely observed by the authors.

\section{Funding/Support}

Ahvaz Jundishapur University of Medical Sciences supported the study (Grant\# CVRC-9605).

\section{References}

1. Jansz TT, Bonenkamp AA, Boereboom FTJ, van Reekum FE, Verhaar MC, van Jaarsveld BC. Health-related quality of life compared between kidney transplantation and nocturnal hemodialysis. PloS one. 2018;13:e0204405.

2. Saran R, Robinson B, Abbott KC, Agodoa LYC, Bhave N, Bragg-Gresham J, et al. US Renal Data System 2017 Annual Data Report: Epidemiology of Kidney Disease in the United States. Am J Kidney Dis. 2018;71:A7.

3. Emara MM, Habeb MA, Alnahal AA, Elshazly TA, Alatawi FO, Masoud AS. Prevalence of pulmonary hypertension in patients with chronic kidney disease on and without dialysis. Egyptian Journal of Chest Diseases and Tuberculosis. 2013;62:761-8.

4. Knight DS, Steeden JA, Moledina S, Jones A, Coghlan JG, Muthurangu V. Left ventricular diastolic dysfunction in pulmonary hypertension predicts functional capacity and clinical worsening: a tissue phase mapping study. J Cardiovasc Magn Reson. 2015;17:116.

5. Bozbas SS, Akcay S, Altin C, Bozbas H, Karacaglar E, Kanyilmaz S, et al. Pulmonary hypertension in patients with end-stage renal disease undergoing renal transplantation. Transplant Proc. 2009;41:2753-6.

6. Mukhtar KN, Mohkumuddin S, Mahmood SN. Frequency of pulmonary hypertension in hemodialysis patients. Pak J Med Sci. 2014;30:1319-22.

7. Nesrallah GE, Lindsay RM, Cuerden MS, Garg AX, Port F, Austin PC, et al. Intensive hemodialysis associates with improved survival compared with conventional hemodialysis. J Am Soc Nephrol. 2012;23:696-705.

8. Kraus MA, Fluck RJ, Weinhandl ED, Kansal S, Copland M, Komenda P, et al. Intensive hemodialysis and health-related quality of life. Am J Kidney Dis. 2016;68:S33-42.

9. Pendse S, Singh AK. Complications of chronic kidney disease: anemia, mineral metabolism, and cardiovascular disease. Med Clin North Am. 2005;89:549-61.

10. Mathew R, Huang J, Wu JM, Fallon JT, Gewitz MH. Hematological disorders and pulmonary hypertension. World J Cardiol. 2016;8:703-18.

11. McCullough PA, Chan CT, Weinhandl ED, Burkart
JM, Bakris GL. Intensive hemodialysis, left ventricular hypertrophy, and cardiovascular disease. Am J Kidney Dis. 2016;68:S5-S14.

12. Bhatti NK, Karimi Galougahi K, Paz Y, Nazif T, Moses JW, Leon MB, et al. Diagnosis and management of cardiovascular disease in advanced and end-stage renal disease. J Am Heart Assoc. 2016;5:e03648. doi: 10.1161/ JAHA.116.003648.

13. Li Z, Liu S, Liang X, Wang W, Fei H, Hu P, et al. Pulmonary hypertension as an independent predictor of cardiovascular mortality and events in hemodialysis patients. Int Urol Nephrol. 2014;46:141-9.

14. Shen S, Sun Q. Analysis of clinically relevant factors for pulmonary hypertension in maintenance hemodialysis patients. Med Sci Monit. 2015;21:4050-6. doi: 10.12659/ msm.895279.

15. Babitt JL, Lin HY. Mechanisms of anemia in CKD. J Am Soc Nephrol.2012;23:1631-4.

16. Vlagopoulos PT, Tighiouart H, Weiner DE, Griffith J, Pettitt D, Salem DN, et al. Anemia as a risk factor for cardiovascular disease and all-cause mortality in diabetes: the impact of chronic kidney disease. J Am Soc Nephrol. 2005; 16:3403-10.

17. Walker AM, Schneider G, Yeaw J, Nordstrom B, Robbins S, Pettitt D. Anemia as a predictor of cardiovascular events in patients with elevated serum creatinine. J Am Soc Nephrol. 2006;17:2293-8.

18. Hertig A, Ferrer-Marin F. Correction of anaemia on dialysis: did we forget physiology? Nephrol Dial Transplant. 2011;26:1120-2.

19. Mimura I, Tanaka T, Nangaku M. How the target hemoglobin of renal anemia should be. Nephron.2015;131:202-9.

20. Chan CT, Liu PP, Arab S, Jamal N, Messner HA. Nocturnal hemodialysis improves erythropoietin responsiveness and growth of hematopoietic stem cells. J Am Soc Nephrol. 2009;20:665-71.

21. Kraus MA, Kansal S, Copland M, Komenda P, Weinhandl $\mathrm{ED}$, Bakris GL, et al. Intensive hemodialysis and potential risks with increasing treatment. Am J Kidney Dis. 2016;68:S51-S8.

22. Cornelis T, Usvyat LA, Tordoir JH, Wang Y, Wong M, Leunissen $\mathrm{KM}$, et al. Vascular access vulnerability in intensive hemodialysis: a significant Achilles' heel? Blood Purif. 2014;37:222-8.

23. Morfin JA, Fluck RJ, Weinhandl ED, Kansal S, McCullough PA, Komenda P. Intensive hemodialysis and treatment complications and tolerability. Am J Kidney Dis. 2016;68:S43-50.

24. Trinh E, Chan CT. Intensive home hemodialysis results in regression of left ventricular hypertrophy and better clinical outcomes. Am J Nephrol. 2016;44:300-7.

25. Nehus E, Goebel J, Mitsnefes M, Lorts A, Laskin B. Intensive hemodialysis for cardiomyopathy associated with end-stage renal disease. Pediatr Nephrol. 2011;26:1909-12.

26. Wu BT, Tsai-Pai MA, Hsu HY, Lin PS, Lin CH, Chen YT. Effect of preload reduction by hemodialysis on left ventricular mechanical parameters by three-dimensional speckle tracking echocardiography. Acta Cardiol Sin. 2012;28:25-33.

27. Antlanger M, Aschauer S, Kopecky C, Hecking M, Kovarik 
JJ, Werzowa J, et al. Heart failure with preserved and reduced ejection fraction in hemodialysis patients: prevalence, disease prediction and prognosis. Kidney Blood Press Res. 2017;42:165-76.

28. Chen R, Wu X, Shen LJ, Wang B, Ma MM, Yang Y, et al. Left ventricular myocardial function in hemodialysis and nondialysis uremia patients: a three-dimensional speckle-tracking echocardiography study. PLoS One. 2014;9:e100265.

29. Denton CP, Cailes JB, Phillips GD, Wells AU, Black CM, Bois
RM. Comparison of Doppler echocardiography and right heart catheterization to assess pulmonary hypertension in systemic sclerosis. Br J Rheumatol. 1997;36:239-43. doi: 10.1093/rheumatology/36.2.239.

30. Augustine DX, Coates-Bradshaw LD, Willis J, Harkness A, Ring L, Grapsa J, et al. Echocardiographic assessment of pulmonary hypertension: a guideline protocol from the British Society of Echocardiography. Echo Res Pract. 2018;5:G11-24.

Copyright (c) 2021 The Author(s); Published by Nickan Research Institute. This is an open-access article distributed under the terms of the Creative Commons Attribution License (http://creativecommons.org/licenses/by/4.0), which permits unrestricted use, distribution, and reproduction in any medium, provided the original work is properly cited. 